\title{
Penerapan Konsep Non-Deterministic Finite Automata (NFA) pada Aplikasi Simulasi Mesin Kopi Vending
}

\author{
Benny Richardson ${ }^{1}$, Kevin Hendy ${ }^{2}$, Ventryshia Andiyani ${ }^{3}$, dan Wilson Philips ${ }^{4}$ \\ 1,2,3,4 Fakultas Teknik dan Informatika, Universitas Multimedia Nusantara, \\ Jl. Scientia Boulevard, Gading Serpong, Tangerang, Banten, Indonesia \\ e-mail: ${ }^{1,2,3,4}$ \{ benny.richardson, kevin.hendy, ventryshia.andiyani, wilson4\} @ student.umn.ac.id
}

\begin{abstract}
Abstrak
In this research, an application for the simulation of vending coffee machines will be discussed using the concept of Non-Deterministic Finite Automata (NFA). With the projected growth in coffee consumption in Indonesia, which increases every year, vending machines can be one of the innovations that can be applied to coffee machines. This coffee vending machine can make 6 coffee variants, with its temperature and desired glass size. There is also a system of cash payments that are applied to this vending coffee machine, where the change will be issued according to the excess balance that is available. The method used is the formal method, to link the design of formal specifications with the application flowchart. Based on the test results obtained, the concept of Non-Deterministic Finite Automata (NFA) can be used as an alternative in the design of vending coffee machines.
\end{abstract}

Keywords: Coffee Machines, Non-Deterministic Finite Automata, Automata Theory and Languages

\section{Pendahuluan}

Kopi sudah menjadi minuman yang banyak digemari masyarakat Indonesia. Hal ini terbukti dari proyeksi pertumbuhan konsumsi produk kopi olahan dalam negeri yang meningkat rata-rata $7 \%$ setiap tahunnya (Yolanda, 2018). Ditambah pula dengan preferensi rasa kopi setiap orang yang bermacam-macam, peningkatan konsumsi kopi ini memberi tuntutan inovasi pada mesin kopi vending yang dapat membuat beragam varian rasa kopi secara efisien dan akurat.

Terdapat penelitian terdahulu yang sejenis (Rizky Indah Melly E.P, 2012)mengenai penerapan konsep finite state automata (FSA) mesin pembuat kopi otomatis. Akan tetapi, pada penelitian tersebut belum diterapkan sistem pembayaran, beserta variasi suhu dan ukuran gelas kopi yang dapat dipilih. Sehingga pada penelitian ini akan dihasilkan aplikasi simulasi mesin kopi vending, yang dapat menangani transaksi pembayaran cash serta membuat kopi sesuai pilihan variasi rasa, suhu, dan ukuran gelas kopi yang diinginkan.

\section{Metode Penelitian}

Pada penelitian ini digunakan metode formal untuk menghubungkan rancangan spesifikasi formal yang dibuat dengan flowchart aplikasi. Metode formal merupakan suatu pemodelan matematika, yang dapat digunakan untuk menjembatani (spesifikasi formal) pembuatan, pengembangan dan verifikasi perangkat keras dan piranti lunak, yang dapat digunakan dari perancangan awal hingga pengujian hasil yang diperoleh (Butler, 2018).

\subsection{Perancangan State Diagram}

Teknik spesifikasi formal yang digunakan yaitu dengan membuat state diagram sebagai model perilaku sebuah sistem. State diagram ini akan menjadi dasar dalam pendefinisian tupel dan perancangan flowchart program nantinya. Jenis state diagram yang digunakan yaitu mealy machines dengan konsep Non-Deterministic Finite Automata (NFA). Dengan mealy machines akan terlihat output yang dikeluarkan pada setiap transisi antar state yang terjadi berdasarkan inputan yang diterima dan state sebelumnya.

Terdapat juga batasan masalah dalam state diagram ini, dimana inputan uang yang diterima hanya berupa lembaran Rp 5.000 atau $\mathrm{Rp} 10.000$, dan inputan tambahan bahan ekstra pada kopi maksimal sebanyak 2 kali. Bahan ekstra yang dapat dipilih ialah gula, kopi, susu, dan coklat. Output kopi yang dikeluarkan dapat berupa salah satu dari enam varian rasa kopi yang disediakan. Enam varian kopi tersebut antara lain: espresso, americano, caffee latte, cappuccino, caffe macchiato, dan caffe mocha. Harga kopi juga dibedakan sesuai dengan ukuran gelas kopi yang 
dipilih, antara lain: small seharga $\mathrm{Rp}$ 5.000, medium seharga $\mathrm{Rp} 10.000$, dan large seharga $\mathrm{Rp}$. 15.000 .

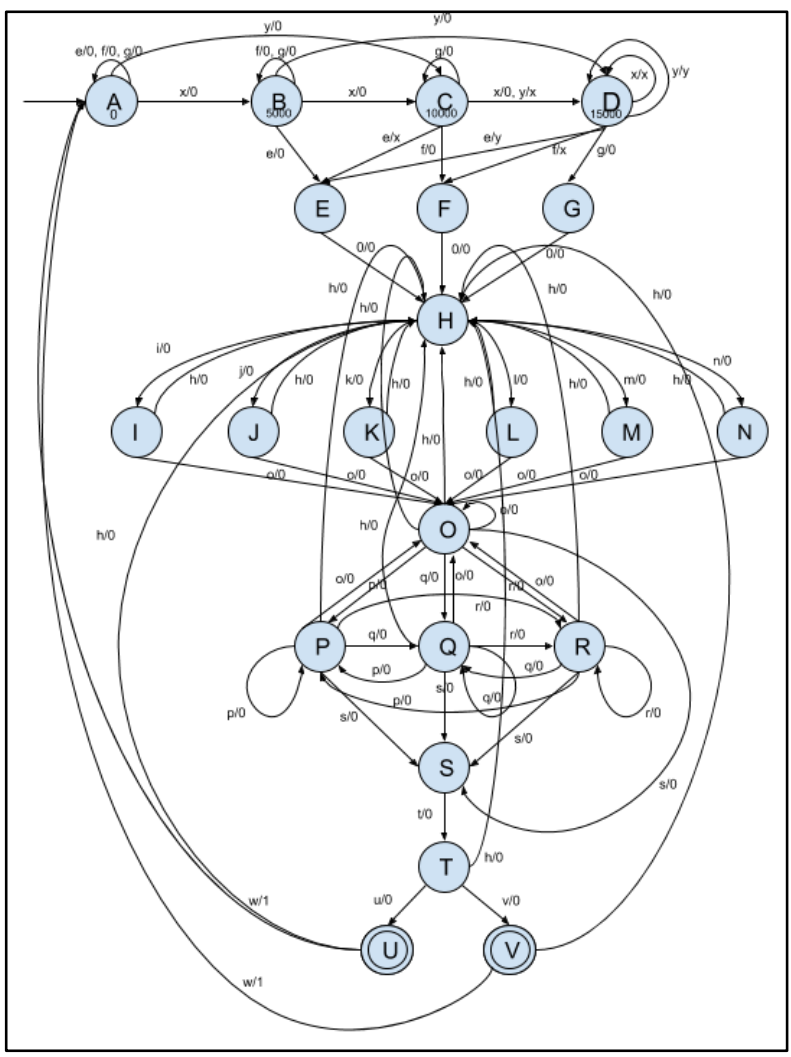

Gambar 1. State Diagram Aplikasi

Pada gambar state diagram diatas dapat dilihat inputan uang yang diterima yaitu $\mathrm{x}$ (lembar uang $\mathrm{Rp}$ 5.000) dan y (lembar uang Rp 10.000). Setiap kali dimasukkan uang, akan terjadi transisi pada state A (Saldo Rp 0), B (Saldo Rp 5.000), C (Saldo Rp 10.000), dan D (Saldo Rp 15.000). Ketika saldo sudah mencapai Rp 15.000, tidak dapat diterima inputan uang lagi, sehingga mesin akan mengeluarkan output langsung sesuai dengan inputan uang $\mathrm{x}$ atau y yang dimasukkan. Setelah dimasukkan uang, dapat diinput ukuran gelas kopi yang diinginkan, yaitu e (memilih gelas kecil), f (memilih gelas sedang), dan $\mathrm{g}$ (memilih gelas besar). Mesin akan mengeluarkan kembalian jika ada. Sebaliknya jika tidak ada kembalian, output yang dikeluarkan bernilai 0 (NULL). Selain output, terdapat juga inputan 0 (NULL) dimana state dapat berpindah langsung ke state selanjutnya tanpa menerima inputan apa-apa.

Setelah memilih ukuran gelas, dapat diinput variasi rasa kopi yang diinginkan, antara lain i (memilih espresso), j (memilih americano), $\mathrm{k}$ (memilih caffee latte), 1 (memilih cappuccino), $\mathrm{m}$ (caffee macchiatto), dan $\mathrm{n}$ (memilih caffee mocha). Inputan gula kemudian akan ditambahkan secara otomatis sebagai salah satu bahan utama untuk membuat kopi. Terdapat juga bahan ekstra yang dapat diinput maksimal sebanyak 2 kali, yaitu o (memilih gula), p (memilih kopi), q (memilih susu), dan $\mathrm{r}$ (memilih coklat). Selanjutnya, mesin akan dimasukkan inputan $\mathrm{s}$ (menambahkan sedikit air) untuk melarutkan bahan-bahan yang dicampurkan pada kopi, dan $t$ (aduk) untuk mengaduk kopi. Setelah itu dapat dipilih suhu kopi yang diinginkan, yaitu $\mathrm{u}$ (memilih hot) dan $\mathrm{v}$ (memilih iced). Jika ingin membatalkan inputan variasi rasa kopi yang dipilih, dapat diinput $\mathrm{h}$ (reset) untuk kembali mengulang inputan ke state H. Sedangkan jika ingin memproses inputan, dapat diinput $\mathrm{w}$ (proses) untuk membuat kopi. Mesin kemudian akan mengeluarkan output bernilai 1 (mengeluarkan kopi) dan kembali ke state awal untuk memproses transaksi pembelian kopi yang baru.

\subsection{Pendefinisian Tupel}

Mealy machine didefinisikan dalam 6 tupel, dengan rumus $\mathrm{M}=(\mathrm{Q}, \Sigma, \delta, \mathrm{S}, \Delta, \lambda)$, dimana :

$\mathrm{Q}=$ himpunan state

$\Sigma=$ himpunan simbol input

$\Delta=$ fungsi transisi $(\delta: \mathrm{Q} \times \Sigma \rightarrow \mathrm{Q})$

$\mathrm{S}=$ state awal (initial state)

$\Delta=$ himpunan output

$\lambda=$ fungsi output untuk setiap transisi

Berdasarkan pendefinisian tersebut, dapat dibuat konfigurasi mesin sebagai berikut:

$\mathrm{Q}=\{\mathrm{A}, \mathrm{B}, \mathrm{C}, \mathrm{D}, \mathrm{E}, \mathrm{F}, \mathrm{G}, \mathrm{H}, \mathrm{I}, \mathrm{J}, \mathrm{K}, \mathrm{L}, \mathrm{M}$, N, O, P, Q, R, S, T, U, V \}

$\Sigma=\{\mathrm{e}, \mathrm{f}, \mathrm{g}, \mathrm{h}, \mathrm{I}, \mathrm{j}, \mathrm{k}, \mathrm{l}, \mathrm{m}, \mathrm{n}, \mathrm{o}, \mathrm{p}, \mathrm{q}, \mathrm{r}, \mathrm{s}, \mathrm{t}$, $\mathrm{u}, \mathrm{x}, \mathrm{y}, \mathrm{z}, 0,1\}$

$\delta(\mathrm{A}, \mathrm{e})=\mathrm{A} ; \delta(\mathrm{A}, \mathrm{f})=\mathrm{A} ; \delta(\mathrm{A}, \mathrm{g})=\mathrm{A} ;$

$\delta(\mathrm{A}, \mathrm{x})=\mathrm{B} ; \delta(\mathrm{A}, \mathrm{y})=\mathrm{C}$;

$\delta(\mathrm{B}, \mathrm{f})=\mathrm{B} ; \delta(\mathrm{B}, \mathrm{g})=\mathrm{B}$;

$\delta(\mathrm{B}, \mathrm{x})=\mathrm{C} ; \delta(\mathrm{B}, \mathrm{y})=\mathrm{D}$;

$\delta(\mathrm{C}, \mathrm{g})=\mathrm{C} ; \delta(\mathrm{C}, \mathrm{x})=\mathrm{D} ; \delta(\mathrm{C}, \mathrm{y})=\mathrm{D}$;

$\delta(\mathrm{D}, \mathrm{x})=\mathrm{D} ; \delta(\mathrm{D}, \mathrm{y})=\mathrm{D} ;$

$\delta(\mathrm{B}, \mathrm{e})=\mathrm{E} ; \delta(\mathrm{C}, \mathrm{e})=\mathrm{E} ; \delta(\mathrm{D}, \mathrm{e})=\mathrm{E} ;$

$\delta(\mathrm{C}, \mathrm{f})=\mathrm{F} ; \delta(\mathrm{D}, \mathrm{f})=\mathrm{F} ; \delta(\mathrm{D}, \mathrm{g})=\mathrm{G}$;

$\delta(\mathrm{E}, 0)=\mathrm{H} ; \delta(\mathrm{F}, 0)=\mathrm{H} ; \delta(\mathrm{G}, 0)=\mathrm{H}$;

$\delta(\mathrm{H}, \mathrm{i})=\mathrm{I} ; \delta(\mathrm{H}, \mathrm{j})=\mathrm{J} ; \delta(\mathrm{H}, \mathrm{k})=\mathrm{K}$;

$\delta(\mathrm{H}, \mathrm{l})=\mathrm{L} ; \delta(\mathrm{H}, \mathrm{m})=\mathrm{M} ; \delta(\mathrm{H}, \mathrm{n})=\mathrm{N}$;

$\delta(\mathrm{I}, \mathrm{h})=\mathrm{H} ; \delta(\mathrm{J}, \mathrm{h})=\mathrm{H} ; \delta(\mathrm{K}, \mathrm{h})=\mathrm{H}$;

$\delta(\mathrm{L}, \mathrm{h})=\mathrm{H} ; \delta(\mathrm{M}, \mathrm{h})=\mathrm{H} ; \delta(\mathrm{N}, \mathrm{h})=\mathrm{H}$;

$\delta(\mathrm{I}, \mathrm{o})=\mathrm{O} ; \delta(\mathrm{J}, \mathrm{o})=\mathrm{O} ; \delta(\mathrm{K}, \mathrm{o})=\mathrm{O}$;

$\delta(\mathrm{L}, \mathrm{o})=\mathrm{O} ; \delta(\mathrm{M}, \mathrm{o})=\mathrm{O} ; \delta(\mathrm{N}, \mathrm{o})=\mathrm{O}$;

$\delta(\mathrm{O}, \mathrm{o})=\mathrm{O} ; \delta(\mathrm{O}, \mathrm{h})=\mathrm{H} ; \delta(\mathrm{O}, \mathrm{p})=\mathrm{P}$;

$\delta(\mathrm{O}, \mathrm{q})=\mathrm{Q} ; \delta(\mathrm{O}, \mathrm{r})=\mathrm{R}$;

$\delta(\mathrm{P}, \mathrm{p})=\mathrm{P} ; \delta(\mathrm{P}, \mathrm{h})=\mathrm{H} ; \delta(\mathrm{P}, \mathrm{q})=\mathrm{Q}$;

$\delta(\mathrm{P}, \mathrm{o})=\mathrm{O} ; \delta(\mathrm{P}, \mathrm{r})=\mathrm{R} ; \delta(\mathrm{P}, \mathrm{s})=\mathrm{S}$; 
$\delta(\mathrm{Q}, \mathrm{p})=\mathrm{P} ; \delta(\mathrm{Q}, \mathrm{h})=\mathrm{H} ; \delta(\mathrm{Q}, \mathrm{q})=\mathrm{Q} ;$ $\delta(\mathrm{Q}, \mathrm{o})=\mathrm{O} ; \delta(\mathrm{Q}, \mathrm{r})=\mathrm{R} ; \delta(\mathrm{Q}, \mathrm{s})=\mathrm{S} ;$ $\delta(\mathrm{R}, \mathrm{p})=\mathrm{P} ; \delta(\mathrm{R}, \mathrm{h})=\mathrm{H} ; \delta(\mathrm{R}, \mathrm{q})=\mathrm{Q}$; $\delta(\mathrm{R}, \mathrm{o})=\mathrm{O} ; \delta(\mathrm{R}, \mathrm{r})=\mathrm{R} ; \delta(\mathrm{R}, \mathrm{s})=\mathrm{S}$; $\delta(\mathrm{S}, \mathrm{t})=\mathrm{T} ; \delta(\mathrm{T}, \mathrm{u})=\mathrm{U}$; $\delta(\mathrm{T}, \mathrm{v})=\mathrm{V} ; \delta(\mathrm{T}, \mathrm{h})=\mathrm{H}$; $\delta(\mathrm{U}, \mathrm{w})=\mathrm{A} ; \delta(\mathrm{U}, \mathrm{h})=\mathrm{H}$; $\delta(\mathrm{V}, \mathrm{w})=\mathrm{A} ; \delta(\mathrm{V}, \mathrm{h})=\mathrm{H}$; $\mathrm{S}=\{\mathrm{A}\}$ $\Delta=\{0,1, \mathrm{x}, \mathrm{y}\}$ $\lambda(\mathrm{A}, \mathrm{e})=0 ; \lambda(\mathrm{A}, \mathrm{f})=0 ; \lambda(\mathrm{A}, \mathrm{g})=0$; $\lambda(\mathrm{A}, \mathrm{x})=0 ; \lambda(\mathrm{A}, \mathrm{y})=0$; $\lambda(\mathrm{B}, \mathrm{f})=0 ; \lambda(\mathrm{B}, \mathrm{g})=0$; $\lambda(\mathrm{B}, \mathrm{x})=0 ; \lambda(\mathrm{B}, \mathrm{y})=0$; $\lambda(\mathrm{C}, \mathrm{g})=0 ; \lambda(\mathrm{C}, \mathrm{x})=0 ; \lambda(\mathrm{C}, \mathrm{y})=\mathrm{x}$; $\lambda(\mathrm{D}, \mathrm{x})=\mathrm{x} ; \lambda(\mathrm{D}, \mathrm{y})=\mathrm{y}$; $\lambda(\mathrm{B}, \mathrm{e})=0 ; \lambda(\mathrm{C}, \mathrm{e})=\mathrm{x} ; \lambda(\mathrm{D}, \mathrm{e})=\mathrm{y}$; $\lambda(\mathrm{C}, \mathrm{f})=0 ; \lambda(\mathrm{D}, \mathrm{f})=\mathrm{x} ; \lambda(\mathrm{D}, \mathrm{g})=0$; $\lambda(\mathrm{E}, 0)=0 ; \lambda(\mathrm{F}, 0)=0 ; \lambda(\mathrm{G}, 0)=0$; $\lambda(\mathrm{H}, \mathrm{i})=0 ; \lambda(\mathrm{H}, \mathrm{j})=0 ; \lambda(\mathrm{H}, \mathrm{k})=0$; $\lambda(\mathrm{H}, \mathrm{l})=0 ; \lambda(\mathrm{H}, \mathrm{m})=0 ; \lambda(\mathrm{H}, \mathrm{n})=0$; $\lambda(\mathrm{I}, \mathrm{h})=0 ; \lambda(\mathrm{J}, \mathrm{h})=0 ; \lambda(\mathrm{K}, \mathrm{h})=0$; $\lambda(\mathrm{L}, \mathrm{h})=0 ; \lambda(\mathrm{M}, \mathrm{h})=0 ; \lambda(\mathrm{N}, \mathrm{h})=0$; $\lambda(\mathrm{I}, \mathrm{o})=0 ; \lambda(\mathrm{J}, \mathrm{o})=0 ; \lambda(\mathrm{K}, \mathrm{o})=0$; $\lambda(\mathrm{L}, \mathrm{o})=0 ; \lambda(\mathrm{M}, \mathrm{o})=0 ; \lambda(\mathrm{N}, \mathrm{o})=0$; $\lambda(\mathrm{O}, \mathrm{o})=0 ; \lambda(\mathrm{O}, \mathrm{h})=0 ; \lambda(\mathrm{O}, \mathrm{p})=0$; $\lambda(\mathrm{O}, \mathrm{q})=0 ; \lambda(\mathrm{O}, \mathrm{r})=0$; $\lambda(\mathrm{P}, \mathrm{p})=0 ; \lambda(\mathrm{P}, \mathrm{h})=0 ; \lambda(\mathrm{P}, \mathrm{q})=0$; $\lambda(\mathrm{P}, \mathrm{r})=0 ; \lambda(\mathrm{P}, \mathrm{s})=0 ; \lambda(\mathrm{P}, \mathrm{o})=0$; $\lambda(\mathrm{Q}, \mathrm{p})=0 ; \lambda(\mathrm{Q}, \mathrm{h})=0 ; \lambda(\mathrm{Q}, \mathrm{q})=0$; $\lambda(\mathrm{Q}, \mathrm{r})=0 ; \lambda(\mathrm{Q}, \mathrm{s})=0 ; \lambda(\mathrm{Q}, \mathrm{o})=0$; $\lambda(\mathrm{R}, \mathrm{p})=0 ; \lambda(\mathrm{R}, \mathrm{h})=0 ; \lambda(\mathrm{R}, \mathrm{q})=0$; $\lambda(\mathrm{R}, \mathrm{r})=0 ; \lambda(\mathrm{R}, \mathrm{s})=0 ; \lambda(\mathrm{R}, \mathrm{o})=0$; $\lambda(\mathrm{S}, \mathrm{t})=0 ; \lambda(\mathrm{T}, \mathrm{u})=0$;

$\lambda(\mathrm{T}, \mathrm{v})=0 ; \lambda(\mathrm{T}, \mathrm{h})=0$;

$\lambda(\mathrm{U}, \mathrm{w})=1 ; \lambda(\mathrm{U}, \mathrm{h})=0$;

$\lambda(\mathrm{V}, \mathrm{w})=1 ; \lambda(\mathrm{V}, \mathrm{h})=0$;

Dapat dilihat sesuai pendefinisan tupel diatas bahwa mesin dimungkinkan untuk tidak terjadi kesalahan dalam memproses sistem pembayaran dan pilihan kopi yang diinginkan. Mesin akan mengikuti alur inputan dimulai saat menerima uang, memilih ukuran gelas, memilih varian rasa, menambah bahan ekstra, dan memilih suhu kopi. Saat diterima inputan proses, mesin akan membaca simbol-simbol masukan yang diterima dan membuat kopi.

\section{3 Implementasi}

Berdasarkan perancangan spesifikasi formal yang telah dibuat, akan diimplementasikan kedalam program aplikasi simulasi dengan menggunakan tools Scratch 2.0. Secara umum, proses alur program dapat dilihat dari flowchart berikut ini:

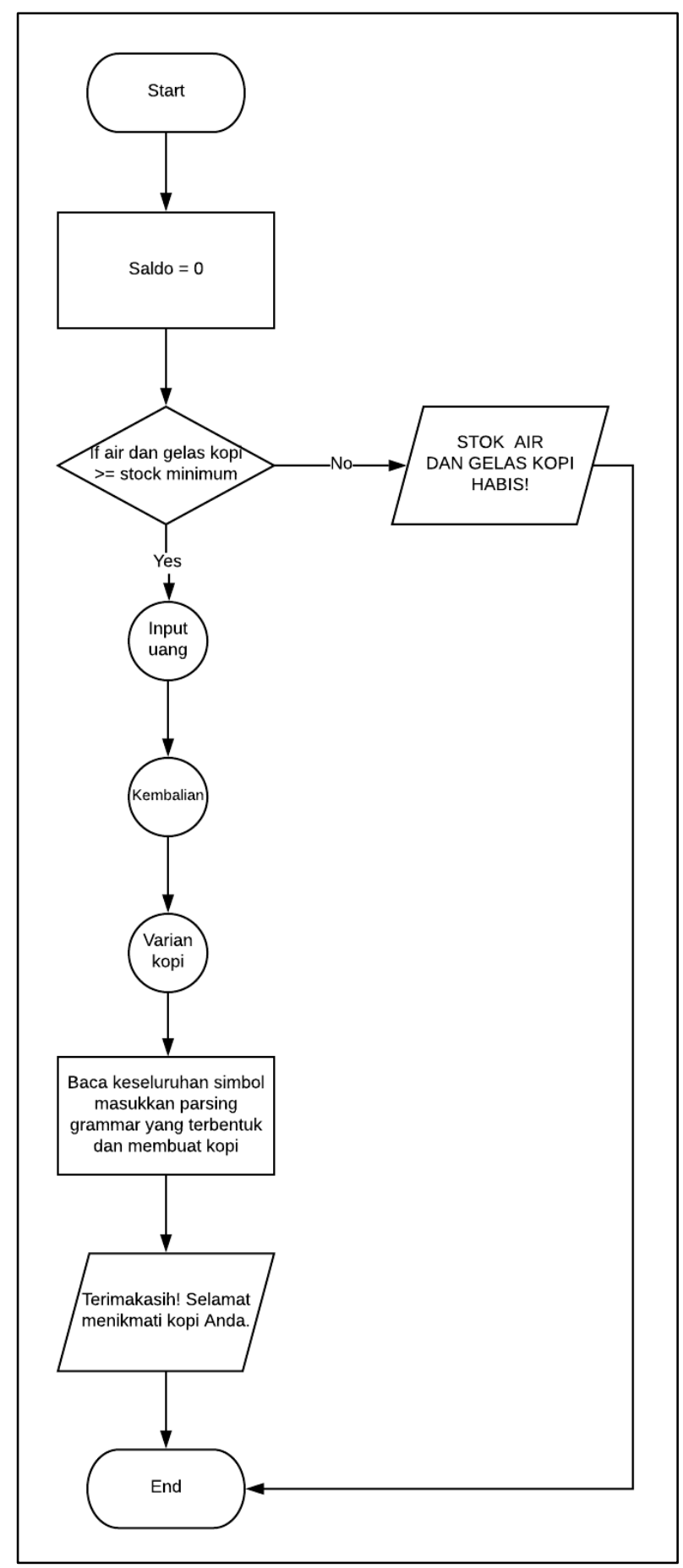

Gambar 2. Main Program 

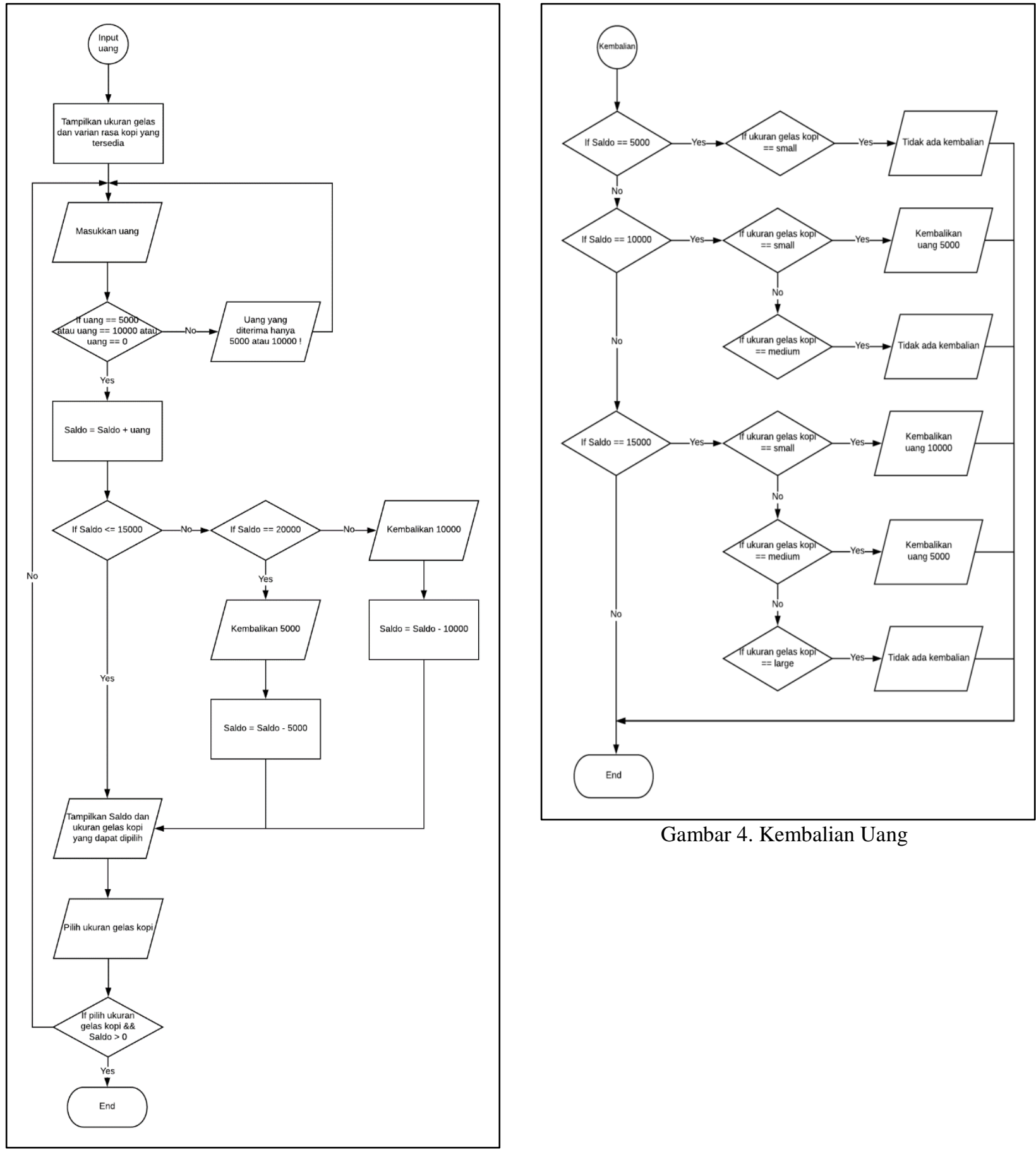

Gambar 4. Kembalian Uang

Gambar 3. Inputan Uang Dan Ukuran Gelas Kopi 


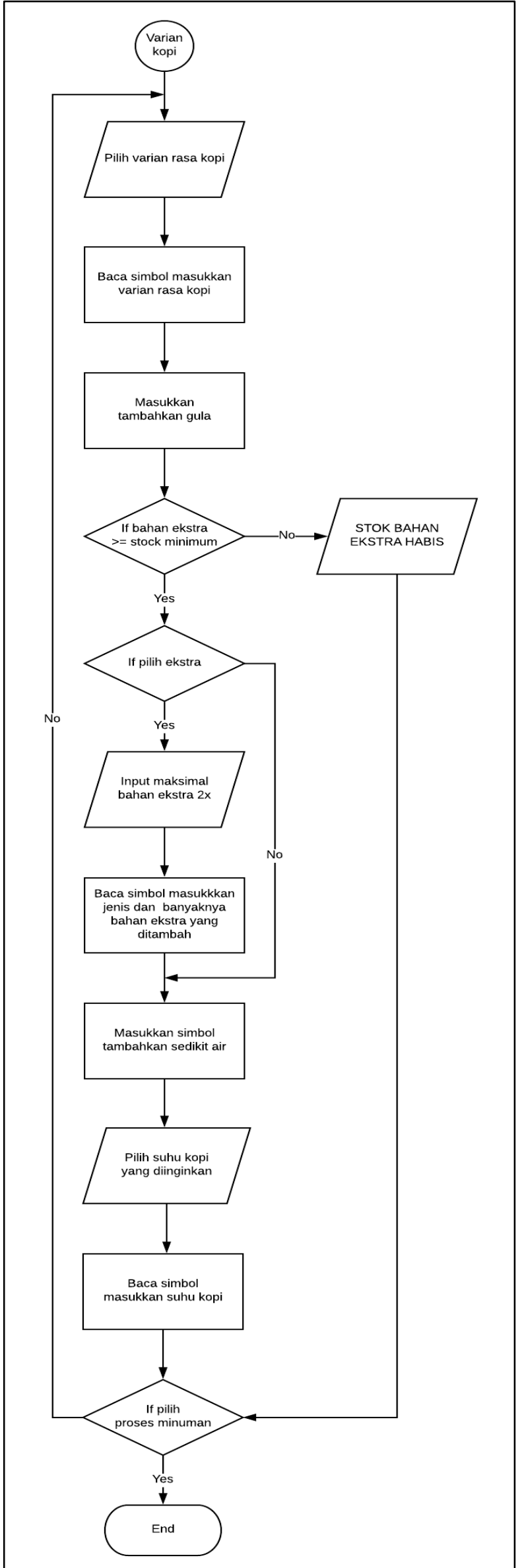

Gambar 5. Varian Kopi

\section{Pembahasan}

Berikut adalah gambar-gambar tampilan interface pada aplikasi simulasi mesin kopi vending yang sudah dibuat:

\subsection{Tampilan Interface}

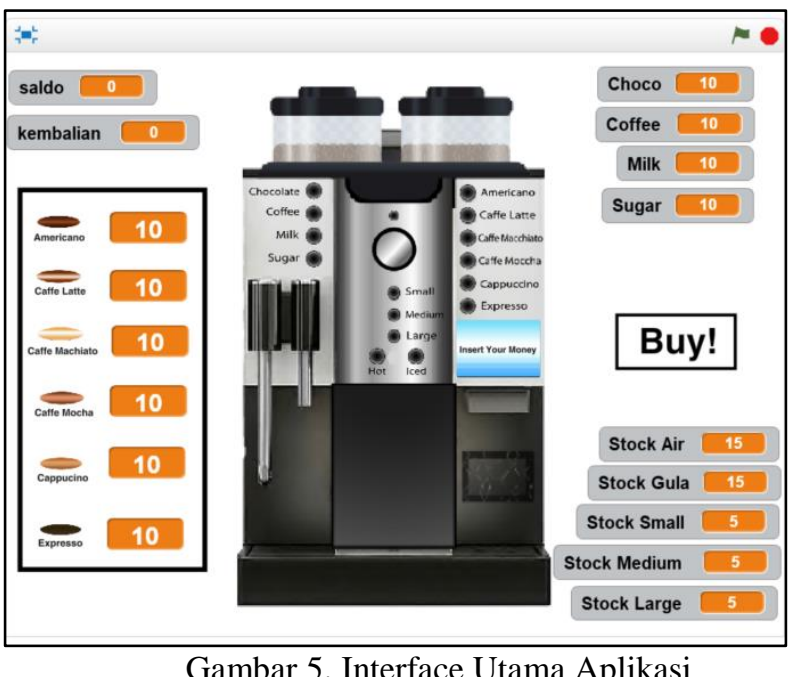

Dapat dilihat pada Gambar 5, mesin mulamula meminta inputan uang untuk memulai transaksi. Saldo akan bertambah sesuai dengan jumlah uang yang dimasukkan. Tombol ukuran gelas yang berwarna merah menandakan inputan ukuran gelas sekarang yang dapat dipilih, sesuai saldo yang ada seperti pada Gambar 6. Saldo yang sudah masuk berjumlah Rp 10.000, sehingga ukuran gelas kopi yang dapat dipilih yaitu small dan medium.

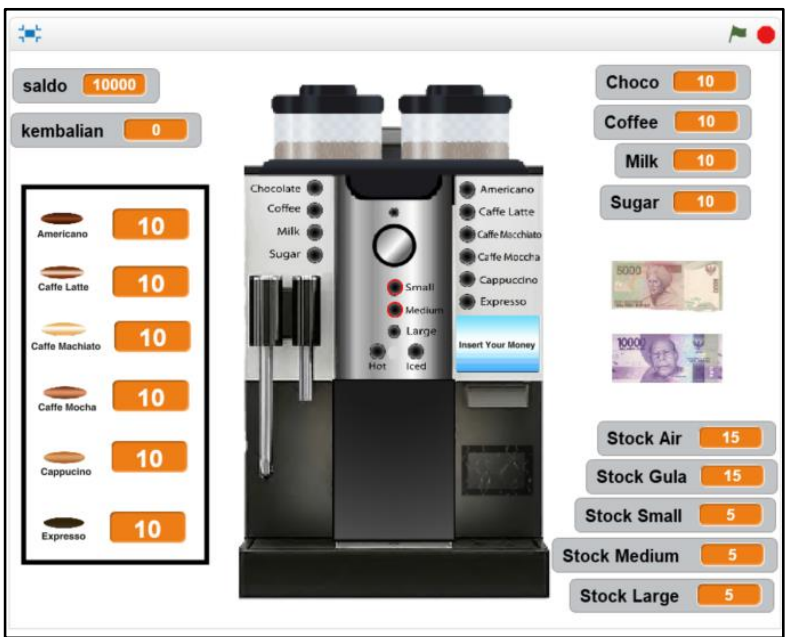

Gambar 6. Saldo Dan Ukuran Gelas Kopi Yang Dapat Dipilih

Jika jumlah saldo sudah melebihi Rp 15.000, akan dikeluarkan kembalian sesuai kelebihan uang yang dimasukkan. Seperti yang 
dapat dilihat pada Gambar 7, kelebihan uang yang dimasukkan adalah Rp 10.000 sehingga uang yang dikembalikan berupa 1 lembar Rp 10.000, seperti yang dapat dilihat pada variabel kembalian. Variabel kembalian ini menunjukkan saldo yang sudah dikembalikkan oleh mesin selama proses transaksi berlangsung. Selanjutnya pada contoh ini akan dipilih ukuran gelas kopi medium seharga Rp. 10.000 .

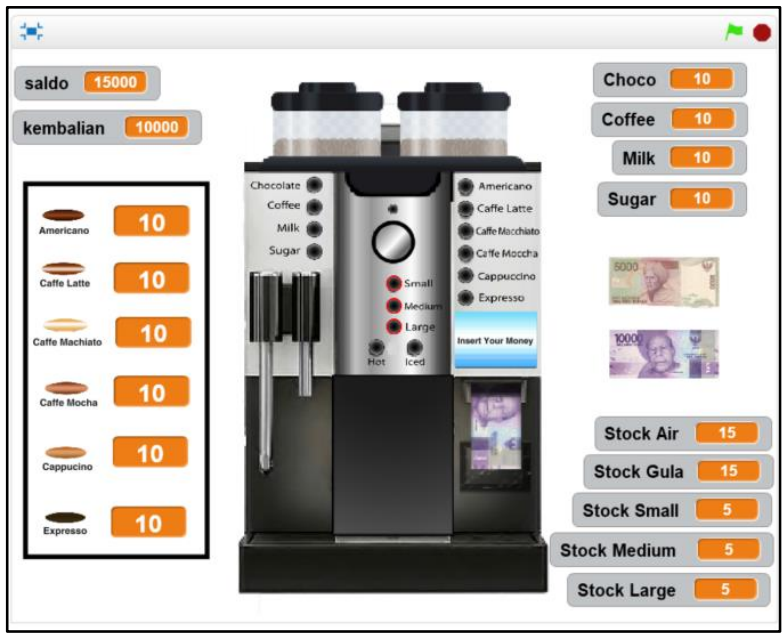

Gambar 7. Kembalian Saat Kelebihan Saldo

Setelah memilih ukuran gelas kopi medium, stok gelas medium akan berkurang 1 poin dan saldo pada mesin dibalikkan menjadi Rp 0 seperti pada Gambar 8. Kelebihan saldo Rp 5.000 akan dikembalikan lagi, sehingga variabel kembalian akan bertambah $\mathrm{Rp} 5.000$ lagi (menjadi Rp 15.000). Kemudian mesin akan meminta inputan varian rasa kopi. Pada contoh ini, varian rasa kopi yang dipilih yaitu cappucino.

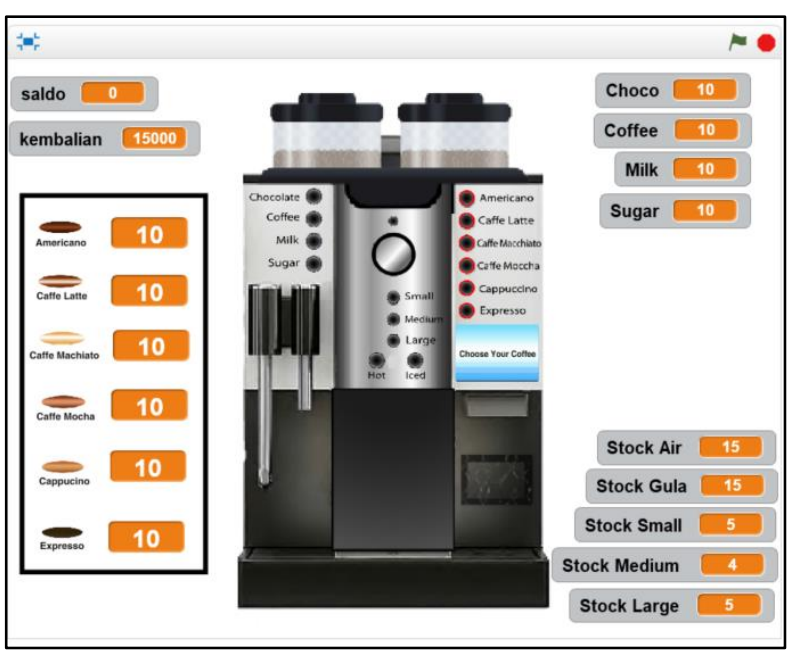

Gambar 8. Pilih Varian Rasa Kopi

Berikutnya pada gambar 9, mesin akan meminta inputan bahan ekstra sebanyak maksimal
2 kali. Tombol bahan ekstra akan otomatis di nonaktifkan jika bahan ekstra yang sudah dipilih 2 kali seperti pada Gambar 10. Selanjutnya dapat dipilih suhu kopi yang diinginkan jika tidak ingin menambahkan bahan ekstra. Pada contoh ini, bahan ekstra yang dipilih yaitu susu sebanyak 2 kali, serta suhu kopi yang diinginkan hot.

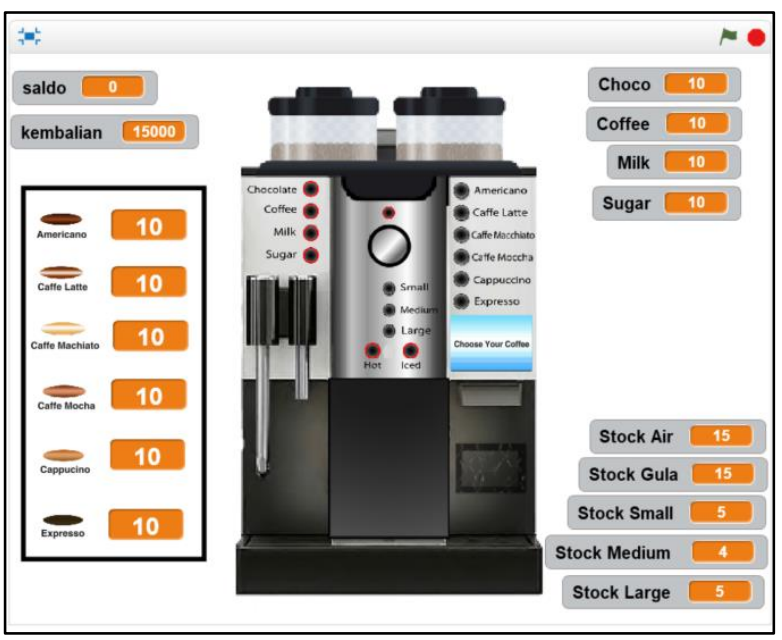

Gambar 9. Pilih Bahan Ekstra dan Suhu

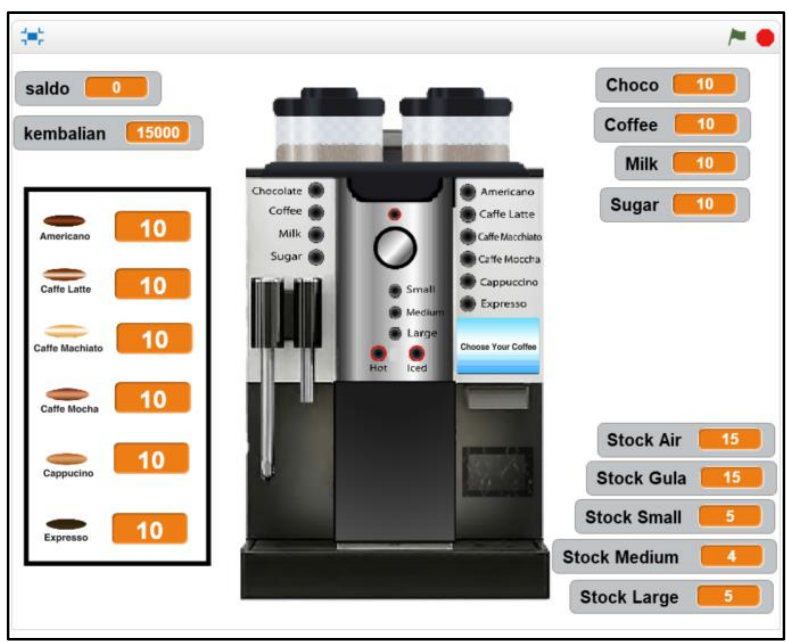

Gambar 10. Pilih Bahan Ekstra dan Suhu

Terdapat tombol reset yang dapat dipilih (tombol kecil diatas tombol proses, tombol proses adalah tombol yang paling besar) jika ingin mengulang kembali inputan, dimulai dari memilih variasi rasa kopi seperti pada Gambar 8 .

Saat dipilih tombol proses, mesin akan membaca semua inputan variasi kopi yang telah dipilih dan mengeluarkan output kopi yang diinginkan. Stok bahan ekstra akan dikurangkan sejumlah inputan bahan ekstra yang dipilih, sedangkan stok air akan dikurangkan sesuai ukuran gelas kopi yang dipilih, seperti pada Gambar 11. Jika ukuran gelas kopi yang dipilih small, stok air akan berkurang 1 poin. Jika ukuran 
gelas kopi yang dipilih medium, stok air akan berkurang 2 poin. Dan jika ukuran gelas kopi yang dipilih large, stok air akan berkurang 3 poin. Demikian pula berlaku untuk pengurangan stok varian rasa kopi dan gula.

Dapat dilihat pada Gambar 11, output kopi yang dikeluarkan sudah sesuai dengan inputan variasi kopi yang dipilih, yaitu kopi cappucino panas dengan tambahan susu 2 kali. Transaksi pembelian kopi pun sudah selesai, dan dapat dipilih tombol buy again untuk memulai transaksi pembelian kopi yang baru.

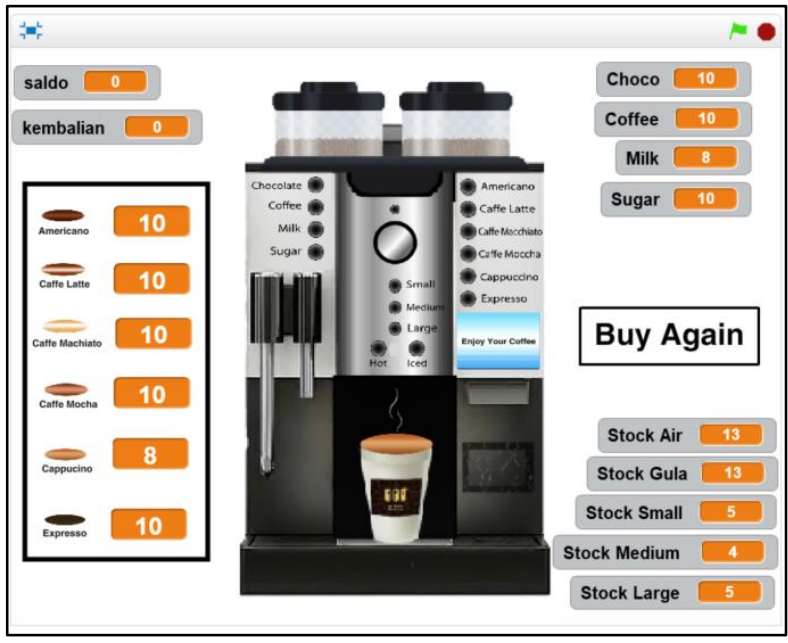

Gambar 11. Output Kopi Dan Pengurangan Stok

Jika salah satu stok bahan utama (air, gula, varian rasa kopi, gelas) habis jumlahnya, maka mesin tidak akan dapat melakukan transaksi apapun, seperti pada Gambar 12. Namun jika stok bahan ekstra yang habis (cokelat, kopi, susu, gula), tombol bahan ekstra yang habis tersebut akan dinonaktifkan.

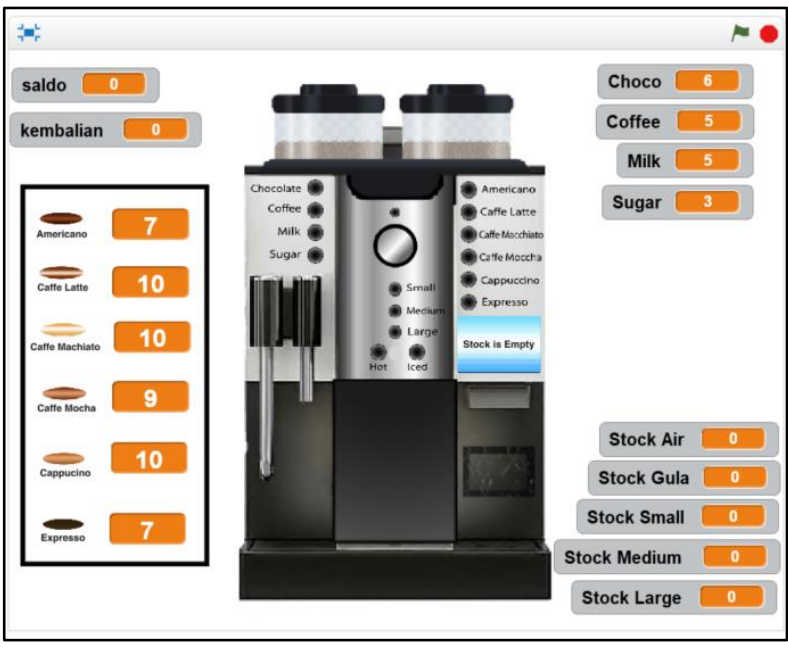

Gambar 12. Stok bahan habis

\subsection{Pengujian}

Metode pengujian yang akan dilakukan dalam penelitian ini adalah model checking.
Dalam model checking ini, akan diuji apakah tampilan interface dan fungsionalitas aplikasi sudah sesuai dengan spesifikasi formal yang dirancang atau tidak. Teknik pengujian dilakukan dengan membuat daftar kemungkinan kesalahan yang dapat terjadi. Urutan alur pengujian akan mengikuti daftar yang sudah dibuat tersebut.

Tabel 1. Daftar Pengujian Aplikasi

\begin{tabular}{|c|c|c|}
\hline No & Pengujian & Detail \\
\hline 1. & $\begin{array}{l}\text { Fungsi } \\
\text { aplikasi }\end{array}$ & $\begin{array}{l}\text { - Kesesuaian output } \\
\text { kembalian (jika ada) dengan } \\
\text { jumlah uang yang dibayar } \\
\text { - Kesesuaian output kopi } \\
\text { dengan inputan } \\
\text { - Kesesuaian output kopi } \\
\text { dengan inputan yang sudah } \\
\text { pernah di reset } \\
\text { - Pengurangan isi stok bahan } \\
\text { sesuai inputan kopi yang } \\
\text { dipilih }\end{array}$ \\
\hline 2. & $\begin{array}{l}\text { Interface } \\
\text { aplikasi }\end{array}$ & $\begin{array}{l}\text { - Kesesuaian inputan rasa, } \\
\text { suhu, dan ukuran gelas kopi } \\
\text { dengan output gambar kopi } \\
\text { yang dikeluarkan } \\
\text { - Mendisable tombol ukuran } \\
\text { gelas kopi yang dapat } \\
\text { dipilih sesuai dengan jumlah } \\
\text { saldo yang dimasukkan } \\
\text { - Mendisable mesin saat } \\
\text { bahan dasar habis } \\
\text { - Mendisable tombol pilihan } \\
\text { bahan ekstra yang tidak } \\
\text { dapat dipilih saat habis } \\
\text { - Mendisable tombol bahan } \\
\text { ekstra yang sudah dipilih } 2 \\
\text { kali } \\
\text { - Kesesuaian kotak dialog } \\
\text { yang ditampilkan dengan } \\
\text { inputan tombol yang dapat } \\
\text { dipilih } \\
\text { - Manipulasi tombol }\end{array}$ \\
\hline
\end{tabular}

Selanjutnya, hasil pengujian dapat dilihat pada tabel dibawah ini.

Tabel 2. Hasil Pengujian Fungsi Aplikasi

\begin{tabular}{|l|l|l|}
\hline No & \multicolumn{1}{|c|}{ Pengujian } & Detail \\
\hline 1. & $\begin{array}{l}\text { Kesesuaian output kembalian } \\
\text { (jika ada) dengan jumlah uang } \\
\text { yang dibayar }\end{array}$ & Baik \\
\hline 2. & $\begin{array}{l}\text { Kesesuaian output kopi } \\
\text { dengan inputan }\end{array}$ & Baik \\
\hline 3. & $\begin{array}{l}\text { Kesesuaian output kopi } \\
\text { dengan inputan yang sudah } \\
\text { pernah di reset }\end{array}$ & Baik \\
\hline 4. & $\begin{array}{l}\text { Pengurangan isi stok bahan } \\
\text { sesuai inputan kopi yang } \\
\text { dipilih }\end{array}$ & Baik \\
\hline
\end{tabular}


Tabel 3. Hasil Pengujian Interface Aplikasi

\begin{tabular}{|l|l|l|}
\hline No & \multicolumn{1}{|c|}{ Pengujian } & Detail \\
\hline 1. & $\begin{array}{l}\text { Kesesuaian inputan rasa, } \\
\text { suhu, dan ukuran gelas } \\
\text { kopi dengan output gambar } \\
\text { kopi yang dikeluarkan }\end{array}$ & Baik \\
\hline 2. & $\begin{array}{l}\text { Mendisable tombol ukuran } \\
\text { gelas kopi yang dapat } \\
\text { dipilih sesuai dengan } \\
\text { jumlah saldo yang } \\
\text { dimasukkan }\end{array}$ & Baik \\
\hline 3. & $\begin{array}{l}\text { Mendisable mesin saat } \\
\text { bahan dasar habis }\end{array}$ & Baik \\
\hline 4. & $\begin{array}{l}\text { Mendisable tombol pilihan } \\
\text { bahan ekstra yang tidak } \\
\text { dapat dipilih saat habis }\end{array}$ & Baik \\
\hline 5. & $\begin{array}{l}\text { Mendisable tombol bahan } \\
\text { ekstra yang sudah dipilih 2 } \\
\text { kali }\end{array}$ & Baik \\
\hline 6. & $\begin{array}{l}\text { Kesesuaian kotak dialog } \\
\text { yang ditampilkan dengan } \\
\text { inputan tombol yang dapat } \\
\text { dipilih }\end{array}$ & Baik \\
\hline 7. & Manipulasi tombol & Baik \\
\hline
\end{tabular}

\section{Kesimpulan}

Berdasarkan hasil pengujian yang telah dilakukan, diperoleh kesimpulan bahwa konsep Non-Deterministic Finite State Automata (NFA) dapat dijadikan sebagai salah satu alternatif dalam perancangan mesin kopi vending. Konsep NFA tersebut diterapkan untuk menangkap pola inputan yang diberikan dan membaca simbol inputan tersebut menjadi bahasa yang dikenali oleh mesin. Proses pembuatan kopi beserta sistem pembayaran akan dikerjakan secara otomatis. Mesin kemudian akan mengeluarkan output yang sesuai.

\section{Saran}

Adapun saran yang dapat dilakukan untuk mengembangkan penelitian yang sejenis, yaitu menambahkan sistem pembayaran secara cashless. Dengan sistem pembayaran cashless ini, uang kembalian dapat ditambahkan secara otomatis ke saldo account pembeli.

\section{Daftar Pustaka}

Butler, R. (2018, November 6). What is Formal Methods? Retrieved from NASA Langley Formal Methods Research Program: https://shemesh.larc.nasa.gov/fm/fmwhat.html

Rizky Indah Melly E.P, W. D. (2012). Penerapan Konsep Finite State Automata (FSA) pada Mesin Pembuat Minuman Kopi Otomatis. Jurnal Komputasi, 95-102.

Yolanda, F. (2018, November 4). Pertumbuhan Konsumsi Kopi Diproyeksi Meningkat Tujuh Persen. Retrieved from Republika: https://republika.co.id/berita/ekonomi/korpora si/18/10/18/pgshsz370-pertumbuhankonsumsi-kopi-diproyeksi-meningkat-tujuhpersen 